\title{
GLOBALGAP HeVi-standardin pilotointi
}

\author{
Piirainen Anne ${ }^{1)}$, Tuominen Riina ${ }^{1)}$ ja Soininen Hanne ${ }^{2)}$ \\ ${ }^{1)}$ Helsingin yliopisto, Ruralia-instituutti, Lönnrotinkatu 7, 50100 Mikkeli,anne.piirainen@helsinki.fi, \\ riina.sh.tuominen@helsinki.fi \\ ${ }^{2)}$ Mikkelin ammattikorkeakoulu, PL 181, 50101 Mikkeli, hanne.soininen@mamk.fi
}

\section{Tiivistelmä}

GLOBALGAP HeVi-standardin pilotointi aloitettiin Etelä-Savossa viljelijöiden käytännön tarpeesta. Pilotointi tehtiin kahden erillisen hankkeen avulla, joiden tavoitteena oli GLOBALGAP-standardin mukaisen ulkoisen auditointivalmiuden saavuttaminen.

Sertifiointivalmiuksia hankittiin $\mathrm{mm}$. tilan johtamiseen, ammatinhallintaan, työturvallisuuteen, elintarviketurvallisuuteen, jäljitettävyyteen, ympäristön huomioimiseen ja työntekijöiden työoloihin liittyvillä koulutuksilla. Koulutuksessa vertailtiin myös erilaisia tuotannonohjaus- ja tuotannonhallintajärjestelmiä sekä testattiin yritykselle parhaiten soveltuvaa järjestelmää. Pilotoinnin osana kehitettiin myös yritysten tuotantoa tuotteiden tuoteturvallisuuden osoittamisen pohjalta. Hankkeen tuloksena kiteytettiin GLOBALGAP-prosessikaavio, joka kuvaa sitä, miten prosessi kannattaa viedä läpi yrityksessä.

Pilotointiin mukaan lähteneistä tiloista kaksi saivat GLOBALGAP-sertifikaatin syksyllä 2010. Toinen tiloista jatkoi uusinta-auditointiin vuonna 2011. Muut valmennuksessa mukana olleet tilat eivät ottaneet ulkoista auditointia vielä tässä vaiheessa auditointikustannusten vuoksi.

GLOBALGAP koetaan käyttökelpoisena laatujärjestelmänä vihannesyrityksissä. Uuden laatujärjestelmän vaatimusten sisäistämistä ei pidetä liian hankalana, mutta apu standardin vaatimusten ymmärtämiseen on kuitenkin monelle tarpeen. Myös kustannuskysymykset GLOBALGAPissa arveluttavat viljelijöitä ja sen takia järjestelmä ei ole pienemmille tiloille kannattava ratkaisu. GLOBALGAPin tulevaisuus on Suomessa vielä epävarma ja nähtäväksi jää yleistyykö se.

Asiasanat: alkutuotanto, puutarhatuotanto, kasvikset, GLOBALGAP, laatujärjestelmä 


\section{Johdanto}

Etelä-Savo on merkittävin avomaalla viljeltävien salaattivihannesten tuotantoalue Suomessa, jäävuorisalaatista ja kiinankaalista noin puolet tuotetaan Etelä-Savossa. Tuotanto suuntautuu pääasiassa tuoremarkkinoille.

Aloite kansainvälisen laatujärjestelmän pilotoimiseksi Etelä-Savossa tuli viljelijöiltä käytännön tarpeeseen, sillä vihannesten vienti oli keskeytynyt EurepGap-standardin puuttumiseen. (EurepGap muuttui GLOBALGAPiksi elokuussa 2008). Tarve hankkeistettiin kahteen erilliseen koulutus- ja kehittämishankkeeseen: Tiedolla ja taidolla tavoitteisiin -koulutuskokonaisuuteen (ESR S10411) kuuluvaan Kasvistuottajien valmennusohjelmaan sekä Vihannesketjun kehittäminen, VIKKE-hankkeeseen. Kasvistuottajien valmennusohjelmassa järjestettiin yritys- ja ryhmäkohtaista koulutusta ja viljelytoimenpiteitä kehitettiin VIKKE-hankkeessa. Hankkeiden tavoitteena oli GLOBALGAP-standardin mukaisen ulkoisen auditointivalmiuden saavuttaminen.

Yritysten valmistautumista ja prosessin vaikutuksia tutkittiin opinnäytetyössä. Tutkimuksen avulla selvitettiin mitä laatujärjestelmä vaatii yritykseltä, mitkä olivat yleisimmät puutteet vaatimuksissa ja mitä etuja järjestelmä tuo yrityksille.

\section{Aineisto ja menetelmät}

GLOBALGAP-pilotoinnin aloitti 14 yritystä, jotka sijaitsivat Etelä-Savon alueella muutamaa poikkeusta lukuun ottamatta. Yrityksistä yksi luopui GLOBALGAP-auditointivalmiuksien tavoittelusta melko varhaisessa vaiheessa ja toinenkin yritys noin puolivälissä valmennusta.

\section{Koulutus}

Auditointivalmiuden saavuttamiseksi hankkeet sisälsivät erilaisia yritys- ja ryhmäkohtaisia sekä yleisiä toimenpiteitä. Valmistautuminen aloitettiin yritysten lähtötason kartoituksella. Kartoituksessa verrattiin yrityksen nykytilaa standardin vaatimuksiin sertifiointikelpoisuuden saavuttamiseksi. Kelpoisuutta parannettiin koulutusten ja yrityskohtaisen opastuksen avulla. Koulutuksia järjestettiin mm. hygieniariskeistä, tuotelaadusta, jätehuollosta ja päästöjen hallinnasta, ensiapuvalmiudesta, pelastussuunnitelman laadinnasta ja viljelyohjelmista.

Standardi edellyttää myös useita suunnitelmia, ohjeistuksia ja riskinarviointeja. Yrityskohtaisten riskienarvioinnin tueksi tehtiin vuokaaviomuotoinen tuotannon toimintojen kuvaus, jossa oli esitetty yrityksen toiminnat sekä arvioitu työsuojelun, tuoteturvallisuuden ja ympäristön kannalta kriittiset pisteet. Riskinarviointi tehtiin terveellisistä ja turvallisista työoloista ja tuoteturvallisuudesta, myös kasteluvesien ja uusien tuotantopaikkojen riskit arvioitiin. Yrityksille tehtiin myös jätehuolto- ja pelastussuunnitelma.

GLOBALGAP-sertifiointiin valmistautuminen edellytti myös yritysten sisäisen auditoinnin suorittamista. Sen avulla selvitettiin, mitkä auditoinnin vaatimukset täyttyvät ja mitä toimenpiteitä yrityksessä tulee tehdä, jotta sertifiointi on mahdollinen.

\section{Tuoteturvallisuuden kehittäminen}

Tuoteturvallisuuden tason osoittamiseksi ja kehittämistoimenpiteiden lähtökohdaksi tehtiin kattava joukko erilaisia analyysejä vihanneksista ja kasteluvedestä. Kasveista analysoitiin nitraattipitoisuuksia, kadmiumpitoisuuksia, mikrobipitoisuuksia ja torjunta-ainejäämiä. Kasteluvesistä analysoitiin aistinvarainen ja mikrobiologinen laatu.

\section{Tulokset ja tulosten tarkastelu}

GLOBALGAP-sertfiointiin valmistautuminen edellyttää yrityksissä usein lukuisia toimenpiteitä. Taulukkoon 1 on koottu pilotoinnin yhteydessä tehtyjä toimenpiteitä sekä kerrottu niiden tarkoitus ja yrityksen käyttämä aika. 
TAULUKKO 1. Pilotoinnin toimenpiteet ja osallistuneiden yritysten määrä sekä toimenpiteiden vaatima keskimääräinen aika yrityksessä ja saavutettu tuotos.

\begin{tabular}{|c|c|c|c|}
\hline Toimenpide & $\begin{array}{l}\text { Yritysten } \\
\mathrm{lkm}\end{array}$ & $\begin{array}{l}\text { Yrityksen } \\
\text { käyttämä } \\
\text { aika, pv }\end{array}$ & Tuotos \\
\hline $\begin{array}{l}\text { Lähtötason kartoitus avustettuna } \\
\text { (versio 3) }\end{array}$ & 15 & 1 & Yrityskohtainen lähtötason kartoitus \\
\hline $\begin{array}{l}\text { Lähtötason kartoitus avustettuna } \\
\text { (versio 4) }\end{array}$ & 2 & 1 & Yrityskohtainen lähtötason kartoitus \\
\hline $\begin{array}{l}\text { Vihannestuotannon kriittisten pistei- } \\
\text { den arviointi }\end{array}$ & 14 & 0,5 & $\begin{array}{l}\text { Yrityskohtainen vuokaavio, jossa kuvattu yrityksen } \\
\text { toiminnat ja arvioitu työsuojelun, tuoteturvallisuuden } \\
\text { ja ympäristön kannalta kriittiset pisteet }\end{array}$ \\
\hline $\begin{array}{l}\text { Jätehuoltokonsultointi ja kasteluvesi- } \\
\text { en riskiarviointi }\end{array}$ & 16 & 0,5 & $\begin{array}{l}\text { Yrityskohtainen jätehuoltosuunnitelmat ja kastelu- } \\
\text { vesien riskienarviointi }\end{array}$ \\
\hline $\begin{array}{l}\text { Työsuojelullisten riskien arviointi } \\
\text { avustettuna }\end{array}$ & 14 & 0,5 & $\begin{array}{l}\text { Yrityskohtainen riskiarvioinnit Työsuojeluhallinnon } \\
\text { Riski-Arvi -ohjelmalla, työsuojelun toimintaohjelma }\end{array}$ \\
\hline Hygieniariskien arviointi avustettuna & 14 & 0,5 & Yrityskohtainen tuotteiden hygieniariskiarviointi \\
\hline Hygieniakoulutus & 13 & 1 & Hygieniapassi \\
\hline EA-1 koulutus & $7+10$ & 2 & EA-1 tiedot ja taidot \\
\hline $\begin{array}{l}\text { Pelastussuunnitelmakoulutus ja - } \\
\text { konsultointi }\end{array}$ & 6 & 1,5 & Yrityskohtainen pelastussuunnitelma \\
\hline $\begin{array}{l}\text { Suunnitteluohjelmakoulutukset (Ag- } \\
\text { rineuvos, Peltotuki Pro, Wisu) }\end{array}$ & $6+6+6$ & 1 & Valmiudet ohjelman käyttöön \\
\hline $\begin{array}{l}\text { Integroidun kasvinsuojelun koulutus } \\
\text { ja seminaari }\end{array}$ & 9 & 1,5 & Tietoa integroidusta kasvinsuojelusta \\
\hline $\begin{array}{l}\text { Työsuojelu- ja CE-merkintä - } \\
\text { koulutus }\end{array}$ & 14 & 0,5 & Tietoa työsuojelusta ja CE-merkinnästä \\
\hline Sisäinen auditointi avustettuna & 2 & 1 & Valmius ulkoiseen auditointiin \\
\hline $\begin{array}{l}\text { Sisäinen auditointi avustettuna ja } 1 . \\
\text { ulkoiseen auditointiin valmistautu- } \\
\text { minen }\end{array}$ & 2 & 3 & Valmius ulkoiseen auditointiin \\
\hline 1.ulkoinen auditointi & 2 & 1 & GLOBALGAP-sertifikaatti \\
\hline $\begin{array}{l}\text { Sisäinen auditointi ja uusinta- } \\
\text { auditointiin valmistautuminen }\end{array}$ & 1 & 1 & GLOBALGAP-sertifikaatin ylläpito \\
\hline Ulkoinen uusinta-auditointi & 1 & 1 & GLOBALGAP-sertifikaatin ylläpito \\
\hline
\end{tabular}




\section{Tuoteturvallisuuden kehittämisen toimenpiteet}

Hankkeessa mukana olevat yritykset pumppaavat kasteluvetensä sellaisenaan syötävien kasvien osien kasteluun: järvistä, lammista, virtaavista vesistöistä (esimerkiksi joet) ja kaivetuista kastelualtaista. Kasteluveden laatuun vaikuttavat muun muassa vesistön laatu ja kohteen hoitotoimenpiteet (kertyneen lietteen ja puuston poisto lähialueelta). Laatuun vaikuttaa oleellisesti alueen läheisyydessä olevan hajaasutusalueen jätevesien käsittely sekä lannoitteiden ja karjalannan käyttö kasteluveden ottokohteen läheisyydessä. Mahdollisia riskitekijöitä voivat aiheuttaa ottokohteisiin myös veden pumppaamiseen käytetty menetelmä sekä tieliikenteen sijoittuminen alueelle.

Hankkeessa yrityksistä otettujen kasteluvesinäytteiden mukaan kasteluvesien laatu täyttää alkutuotantoasetuksen mukaiset laatuvaatimukset, yhtään poikkeavaa tulosta ei esiintynyt. Kuvassa 1 on esitetty kasteluvesinäytteiden tuloksia E. colin osalta, näytteet (yhteensä 40 kappaletta) otettiin analysoitavaksi kesä-elokuussa 2008 eri puolilta Etelä-Savoa.

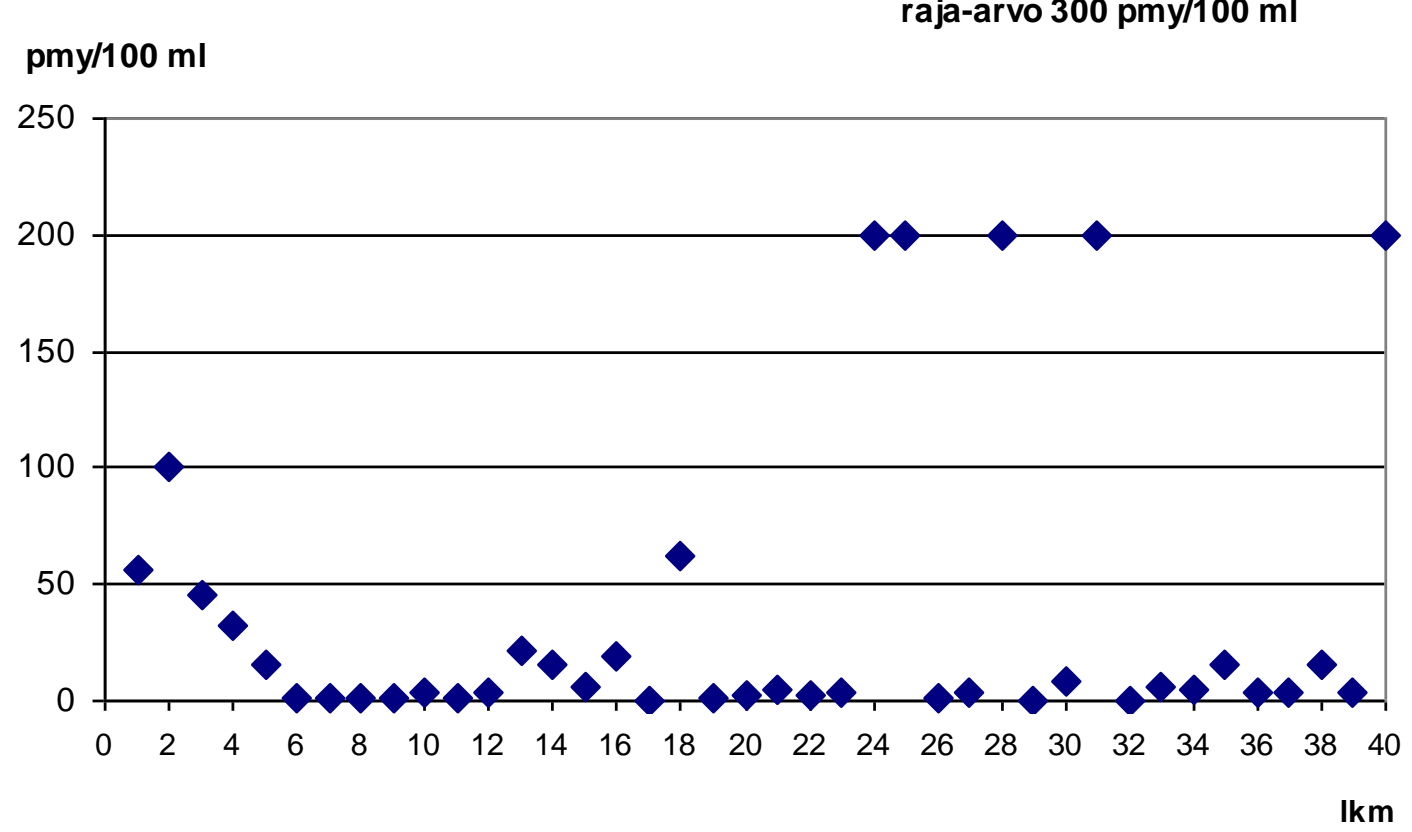

KUVA 1. Kasteluvesinäytteiden analyysituloksia vuodelta 2008 E. colin osalta, näytteet on analysoitu Mikkelin ammattikorkeakoulun ympäristölaboratoriossa.

Nitraattipitoisuudet olivat salaatilla hyvää tasoa, sillä rajan ylityksiä ei havaittu lukuisissa mittauksissa (kuva 2). Nitraatin raja-arvo avomaalla kasvatetulle jäävuorisalaatille on $2000 \mathrm{mg} / \mathrm{kg}$, muille salaateille raja-arvo on 1.4.-30.9. välisenä aikana $2500 \mathrm{mg} / \mathrm{kg}$. Salaattien lisäksi nitraattipitoisuutta mitattiin myös porkkanoista, parsakaalista, kukkakaalista, kiinankaalista keräkaalista ja sipulista. 


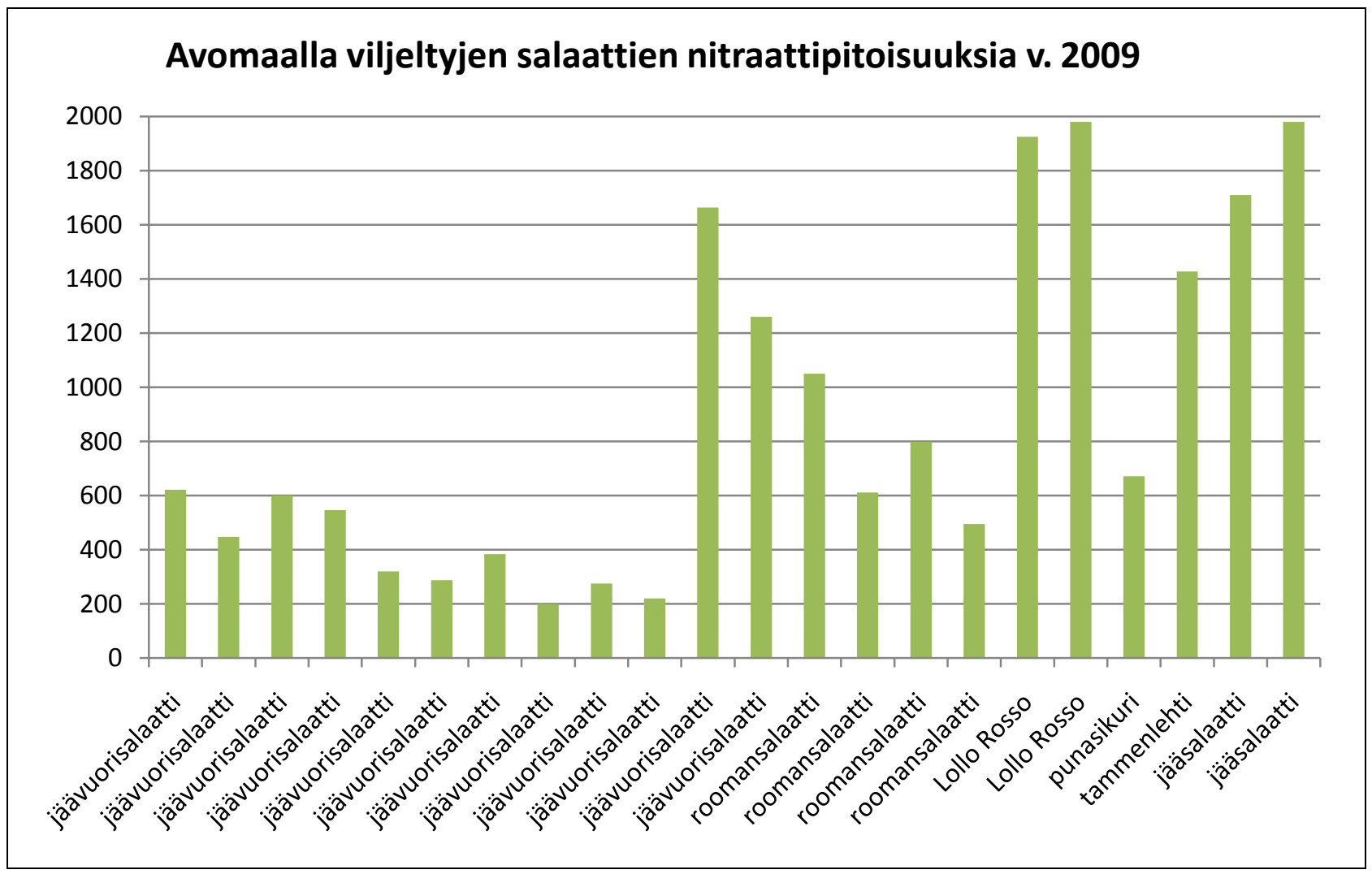

KUVA 2. Eri salaattien nitraattipitoisuuksia kasvukaudella 2009

Mikrobiologisissa analyyseissä mitattiin maanpäällisistä vihanneksista kokonaismikrobipitoisuuksia, enterobakteereja, kolibakteereja, homeita, hiivoja, Bacillus cereusta ja Yersinia pseudotuberculosista, analyysikokoonpanot vaihtelivat vihanneslajin ja analyysivuoden mukaisesti. Tulosten perusteella päädyttiin suosittelemaan vain ruokamyrkytyksiä aiheuttavien patogeenien analysointia, sillä kokonaismikrobipitoisuuksille ei voida asettaa raja-arvoja eikä niiden indikaattoriarvoa patogeenisten mikrobien esiintymisestä voida osoittaa.

Torjunta-ainejäämäpitoisuusanalyyseissä ei havaittu jäämiä torjunta-aineista, eli mahdolliset jäämät jäivät alle analyysirajan.

\section{GLOBALGAP-prosessin eteneminen yrityksessä}

Hankkeen tuloksena kiteytettiin GLOBALGAP-prosessikaavio, joka kuvaa miten prosessi kannattaa viedä läpi yrityksessä (kuva 3). Yritysten tuotantoprosessien kuvaaminen helpottaa yritysten toimintojen ja niihin vaikuttavien tekijöiden hahmottamisessa. Prosessien riskien arvioinnit tuottavat yrityskohtaiset ohjeistukset eri tuotantovaiheisiin. Vaatimukset osaamisesta voidaan saavuttaa koulutusten avulla. Kun vaatimukset on yrityksessä oletettavasti täytetty, suoritetaan uusi itsearviointi tai sisäinen auditointi. Tämän jälkeen valmistaudutaan varsinaiseen auditointiin sekä tehdään vielä mahdolliset korjaukset ja viimeistelevät toimenpiteet. Auditoinnin jälkeen käydään auditoijan kanssa palautekeskustelu, tehdään mahdolliset korjaavat toimenpiteet ja ylläpidetään yrityksen toimintaa ja valmiuksia. 
1. PÄÄTÖS GLOBALGAPLAATUJÄRJESTELMÄÄN VALMISTAUTUMISESTA

\section{LÄHTÖTILANTEEN KARTOITUS}

3. YRITYKSEN

TUOTANTOPROSESSIT

4. RISKIENARVIOINNIT JA SUUNNITELMAT

\section{OSAAMISEN TÄYDENTÄMINEN}

6. TUOTETURVALLISUUS,

YMPÄRISTÖNHOITO JA

LUONNONSUOJELU

\section{AUDITOINTIA EDELTÄVÄ ITSEARVIOINTI/SISÄINEN AUDITOINTI}

\section{VIIMEISET VALMISTELEVAT TOIMENPITEET}

•yrittäjien motivaatio

•tiedottaminen henkilöstölle, määritellään henkilöstön osallistuminen prosessiin (yritys itse määrittelee osallistuvat henkilöt)

•yrityksen lähtötilanteen kartoitus itsearvioinnilla/sisäisellä auditoinnilla

-yhteenvetoraportti ja ehdotukset tehtävistä toimenpiteistä

-tuotantoprosessien kuvaus vuokaavio-muodossa tuote/tuoteryhmäkohtaisesti

- riskienarviointiprosessien läpikäynti

- ohjeistukset riskienarviointien pohjalta

•jätehuoltosuunnitelma

-kouluttautuminen/osaamisen hankkiminen puuttuviin kohtiin (esim. Ensiapu- ja hygieniakoulutukset, työsuojelukoulutus, integroitu kasvinsuojelu)

-tuoteturvallisuustoimenpiteiden suunnittelu ja toteutus (riskienarviointien pohjalta)

-ympäristönhoito- ja luonnosuojelutoimenpiteet - yrityskohtainen suunnitelma, sisältää tuotantotoimenpiteiden ymp.vaikutusten tarkastelun

-2. itsearviointi/sisäinen auditointi

- mahdollisten viimeisten poikkeamien korjaaminen, auditointisopimus auditointiorganisaation kanssa tehdäänviimeistään tässä vaiheessa (viim.3kk ennen auditointia), auditointiajankohdasta sopiminen

- takaisinkutsutestaus ja tuoteturvallisuusanalyysit, jos edellisistä yli 3 kk ennen auditointiajankohtaa tai ei ole tehty aiemmin (ensimmäinen auditointi, sen jälkeen max $12 \mathrm{kk}$ välein)

\section{YHTEENVETO PROSESSISTA JA JATKUVUUDEN TURVAAMINEN}

-palautekeskustelu

- toiminnan jatkuva kehittäminen ja auditointivalmiuksien ylläpito

KUVA 3. GLOBALGAP-prosessi yrityksessä 


\section{Johtopäätökset}

Kansainvälisen laatujärjestelmän avulla tilat voivat kehittää järjestelmällisesti omaa tuotantoaan ja saavuttaa etumatkaa kilpailijoihin nähden. Mikkelin ammattikorkeakoulun ympäristöteknologian (ylempi AMK) koulutusohjelmaan tehdyssä opinnäytetyössä perehdyttiin siihen, mitä laatujärjestelmä vaatii yritykseltä, mitkä olivat yleisimmät puutteet vaatimuksissa ja mitä etuja järjestelmä tuo yrityksille.

Opinnäytetyön mukaan GLOBALGAP koetaan käyttökelpoisena laatujärjestelmänä puutarhatiloilla. Vaikka uuden laatujärjestelmän vaatimusten sisäistäminen vaatii aikaa ja erinäisiä toimenpiteitä, sitä ei pidetä liian hankalana. Apu standardin vaatimusten ymmärtämiseen on kuitenkin monelle tarpeen. Lisäksi kustannuskysymykset GLOBALGAPissa arveluttavat viljelijöitä ja sen takia järjestelmä ei ole pienemmille tiloille kannattava ratkaisu. Kustannuksia tiloille aiheuttavat GLOBALGAPiin valmistautumisen edellä kuvatut toimenpiteet.

GLOBALGAPiin valmentautuneista yrityksistä lähes kaikki noudattivat jo Laatutarha-ohjeistusta, jonka noudattaminen on edellytyksenä sirkkalehtilippumerkin käyttöoikeudelle. Laatuarhan ansiosta yrityksillä oli osasta vaatimuksia kokemuksia. GLOBALGAP ei viljelijöiden mielestä niinkään vaikuta yrityksen toimintaan tai tuo mukanaan täysin uusia toimenpiteitä, vaan lähinnä antaa yrittäjille kokonaisvaltaisemman kuvan yrityksen toiminnoista ja auttaa niiden hallitsemisessa. Laatujärjestelmän avulla yrityksestä voidaan antaa uskottava ja luotettava kuva markkinakumppanina.

Tutkimuksen mukaan (Tuominen 2011) GLOBALGAP-vaatimuksista tiloilla yleisimmin täydennettäviä ovat erilaiset riskinarvioinnit ja yrityskohtaiset suunnitelmat ja ohjeistukset. Tiloilla tulee tehdä riskien arviointeja uusiin tuotantopaikkoihin, työturvallisuuteen, tuotteiden hygieniaan ja kasteluveden laatuun liittyen. Riskinarvioinnin avulla saadaan selville jokaisen arvioidun osa-alueen kohteet, johon huomiota tai toimenpiteitä tulee kohdistaa. Riskinarviointien perusteella voidaan laatia erilaisia yrityskohtaisia ohjeistuksia ja suunnitelmia. Yrittäjien on lisättävä myös osaamistaan ja ainakin todennettava se entistä paremmin. Yrittäjän on osattava myös jakaa osaamistaan, joka ilmenee parhaiten työntekijöiden perehdytystilanteissa.

GLOBALGAPin tulevaisuus on Suomessa vielä epävarma ja nähtäväksi jää yleistyykö se. Laatutarhan harmonisointi GLOBALGAPin kanssa yhteensopivaksi, kuten Ruotsissa Svenskt Sigill -merkin osalta meneteltiin, voisi olla yksi ratkaisu. Selvitystyö kuitenkin jatkuu yhä.

\section{Kirjallisuus}

Piirainen, A. 2009. Savolaiset vihannesviljelijät "maapalloistuvat" - GlogalGAP-laatujärjestelmä tukee kestävää kehitystä, Mikkelin tiedepäivä - Mikkeli Science Day. Uusiutuvien luonnonvarojen hyödyntäminen. Kokous- ja kongressitalo Mikaeli 23.4.2009. 23 s. Suullinen esitys.

Piirainen, A. 2010. Laatujärjestelmät vihannestuottajan näkökulmasta, GLOBALGAP-seminaari 15.4.2010 PTY ry 20 s., suullinen esitys.

Piirainen A., Tuominen R. \& Lehesvaara M. 2011. GLOBALGAP vihannestilojen ympäristöasioiden tukena. Ympäristö ja Terveys. 9/2011.3 s.

Soininen, H. 2009. Kasteluvesien laatu Etelä-Savossa. Mikkelin tiedepäivä - Mikkeli Science Day. Uusiutuvien luonnonvarojen hyödyntäminen. Kokous- ja kongressitalo Mikaeli 23.4.2009. 11 s. Suullinen esitys.

Tuominen, R. 2011. GLOBALGAP-standardi vihannestuotannossa. Opinnäytetyö. Mikkelin ammattikorkeakoulu, ympäristöteknologian koulutusohjelma (YAMK). $84 \mathrm{~s}$.

Tuominen, R. 2011. GlobalGAP - mikä, miksi ja miten? Puutarhasanomat 6/2011. $1 \mathrm{~s}$.

Tuominen, R. 2011. GlobalGAP omavalvonnan tukena. Elintarvike ja Terveys 4/2011. 2 s. www.globalgap.org. 